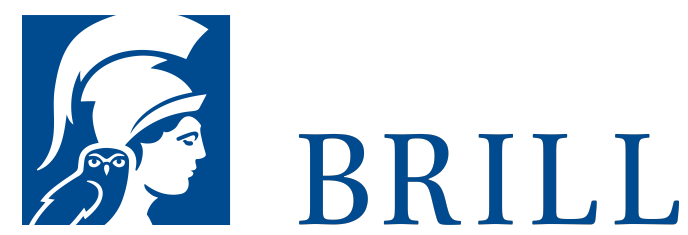

\title{
Über präreflexives Selbstbewusstsein
}

Subpersonale Bedingungen - Empirische Gründe

Author: Marc Borner

Zwischen dem Unbewussten und dem reflexiv Selbstbewussten, dem landläufigen »Ich «, gibt es mentale Zustände, die vor jeglicher Reflexion bestehen. Sie geben eine Antwort auf die Frage »Wer bin ich? - ohne dabei bereits sprachlich verankert zu sein. Diese unsagbaren/unsprachlichen Phänomene einer ursprünglichsten Subjektivität erstmals in den Diskursraum der Bewusstseinsphilosophie einzuholen, ist Ziel der vorliegenden Untersuchung. Das cogito préréflexif der Sartreschen Psychologie erfährt hierbei als Alternative zur Freudschen Psychoanalyse eine erneute Aktualität. Dieses Buch erörtert den Begriff philosophisch vor dem Hintergrund aktueller psychologischer und neurowissenschaftlicher Erkenntnisse. Im Aufweis möglicher subpersonaler Grundlagen präreflexiven Selbstbewusstseins wird die körperliche und emotionale Basis unserer Subjektivität beschrieben. Das vormals »unanalysierbare« Phänomen wird so jenseits metaphorischer und negativer Definitionen neu beleuchtet und damit nicht nur genauer beschrieben, sondern zudem auch noch für einen alternativen Blick auf empirische Untersuchungen sowie für die Beurteilung einer weiten Reihe psychiatrischer und neurologischer Pathologien bedeutsam.

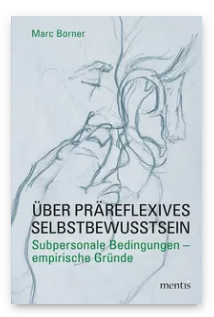

Pages: 377

Seiten

Language:

German

Subjects:

General,

Philosophy

Publisher: Brill | mentis

E-Book (PDF)

Released online: 26 Apr 2016

ISBN: $978-3^{-}$

95743-911-6

List price

Paperback

Publication date:

26 Apr 2016

ISBN: 978-3-

95743-021-2

List price 
For more information see brill.com

Order information: Order online at brill.com +44330 333 0049 | customerservices@brill.com Submission information: brill.com/authors

Titles published by Brill | Fink, Brill | mentis or Brill | Schöningh: +49(o)715413279216| brill@brocom.de 